\title{
MEteor: Developing Physics Concepts Through Body- Based Interaction With A Mixed Reality Simulation
}

\author{
Robb Lindgren*, Michael Tscholl* and J. Michael Moshell† \\ *College of Education, University of Illinois Urbana-Champaign, 1310 S 6th St, Champaign, IL 61820 \\ + School of Visual Arts and Design, University of Central Florida, 12461 Research Parkway Suite 500 \\ Orlando, FL 32826
}

\begin{abstract}
We describe the design and rationale for a project in which a room-sized mixed reality simulation was created to develop middle school students' knowledge and intuitions about how objects move in space. The simulation environment, called MEteor, uses laser-based motion tracking and both floor- and wall-projected imagery to encourage students to use their bodies to enact the trajectory of an asteroid as it travels in the vicinity of planets and their gravitational forces. By embedding students within an immersive simulation and offering novel perspectives on scientific phenomena, the intent is to engage learners in physics education at both an embodied and affective level. We describe a study showing improved attitudes towards science and feelings of engagement and learning for participants who used the whole-body MEteor simulation compared to a desktop computer version of the same simulation. We also discuss general implications for the design of technology-enhanced physics education environments.
\end{abstract}

Keywords: Interactive Simulations, Embodiment, Planetary Astronomy, Mixed Reality, Science Attitudes, Engagement PACS: 01.40.Fk, 01.40.Ha, 01.50.H-

\section{INTRODUCTION}

Emerging research has shown benefits for seeding learning activities within immersive interactive environments. While the focus of this research is primarily on cognitive measures of learning, much less is known about changes in learners' affective states such as attitudes towards science. This paper describes a project that-in addition to addressing other educational outcomes-attempts to increase middleschool children's attitudes towards science and learning experiences through body-based interactions within an immersive simulation of planetary astronomy. While bodily involvement in physics educational activities may not by itself engender robust and enduring understanding of difficult concepts, we hypothesize that certain kinds of embodied interactions can increase students' attitudes towards science and learning and generate new perspectives that afford learning of physics concepts.

The MEteor project is an informal science education initiative that situates learners inside an interactive simulation. One of the project goals is to make physics principles and phenomena less intimidating by pairing them with natural and familiar body movements. This paper describes the design rationale for the MEteor simulation and an empirical study that examines the effects of whole-body interactions with a physics simulation compared to traditional mouse and keyboard controls.

\section{INTERACTIVE PHYSICS SIMULATIONS}

Computer simulations have become an important part of students' learning in a variety of settings. Simulations have unique spatial properties and interactive capabilities that afford conceptual development and facilitate understanding [1]. Appropriately designed simulation environments encourage exploration and inquiry practices, and they are often accompanied by constructivist pedagogies where students are positioned with the agency to create their own knowledge $[2,3]$. The availability of high performance computing and graphical sophistication means that simulations can convey real world phenomena with a high degree of fidelity, while still giving students the control and the opportunity for reflection necessary for an effective learning environment.

While many of the designs of interactive learning simulations have focused on their cognitive affordances [4], affective and motivational factors also play a significant role. For example, modern computer simulations are interactive and they often have a gamelike look and feel. Simulations are generally thought of as being engaging to students and are perceived as being a fun activity [5]. This in turn leads to higher persistence in achieving learning goals and improved learning outcomes [6]. More generally, it has been argued recently that exclusively cognitive design principles are poor predictors of successful learning 
experiences, and calls for a learner-centered design that incorporates affective considerations have become prominent [7]. According to these perspectives, what is central to learning is a student's intellectual and affective engagement with the learning environment. Interactivity, such as the responsiveness of a system to a learner's actions has emerged as an important dimension for engaging the learner. Designing for engagement is therefore often the most important goal in the development of simulations for learning. The PhET suite of interactive simulations, for example, includes engaging students as a top design priority [8]. This is achieved by supporting students' exploration on the basis of their own evolving questions, and by allowing students to set their own learning goals within a science curriculum [9].

The affordances of immersive learning environments align with these theoretical and design approaches to learning: they can increase the degree to which they make a learner feel in control, and are highly responsive to a learner's activities. Examining the influence of interactive physics simulations on attitudes and learning experiences is a nascent and important area of investigation.

\section{EMBODIMENT AND PHYSICS EDUCATION}

Research in philosophy and cognitive science has shown that bodily movement can serve as the starting point for understanding and can scale up to support conceptual knowledge [10]. Studies of specific types of physicality such as gesture demonstrate that bodily movement can influence and offer insights into the process of thinking and learning [11], and recent studies have shown that prompting specific kinds of body movement can serve as an effective educational intervention [12].

The challenge with physics education is that learners often possess misconceptions about physics that are likely incorrect inferences based on previous body experiences (e.g., feeling "pushed" against the door of a car making a sharp turn). The opportunity presented by immersive mixed reality is the ability to connect natural body movements with representational supports (e.g., vectors, trajectories). These connections compel learners to reconcile their intuitions and sensory experiences with the formal principles that govern physical motion. Previous attempts to teach physics using virtual environments and digital simulations have focused on creating controlled interactive spaces for exploration and giving access to phenomena otherwise inaccessible to learners [4]. The MEteor project expands on this work by building a metaphorical connection between body movement and the principles that the learner is trying to understand.

\section{THE METEOR PROJECT: LEARNING PHYSICS THROUGH BODY-BASED METAPHORS}

MEteor is an interactive environment simulating planetary astronomy by projecting planets onto a large (30x10 foot) floor surface. Core to the system is the incorporation of gravitational forces that affect astronomical objects such as asteroids. A learner's task is to launch an asteroid into the simulation space by using a virtual spring, and then to follow it as it is deflected in its path by the gravitational forces of the planets (Figure 1 and Figure 2). The system is made interactive with a laser-based motion-tracking system. This system traces the learner's movements as they attempt to follow the asteroid. A tracking circle projected at the learner's feet (approximately 2 feet in diameter) changes its color from green to red, in relation to the distance between the child and the asteroid. If the distance between the learner and the asteroid gets too large, the asteroid disappears completely and the learner has to re-do the launch. All the feedback and interface supports were designed to keep the learner predicting and tracking the asteroid's movement as closely as possible, so as to enact the correct trajectory resulting from the gravitational forces at play.

Learners initially have control over the trajectory: they determine the position, speed, and angle of the spring launching the asteroid. Immediately after the launch, however, they lose this control and it is the asteroid's momentum and the gravitational forces that take over as the determinants of the trajectory. The learning challenge for participants is to connect the conditions of the initial launch with the trajectory in real time.

More specifically, the design of MEteor scaffolds a learner's developing understanding by engaging her in 4 distinct but related levels. In level 1, learners are given the relatively simple task of hitting a target (a red square) with the asteroid without any gravitational forces present, thus familiarizing them with the basic workings of the spring and also the notion that objects moving in space will move continuously at a constant velocity if not acted upon by other forces. Level 2 adds a large planet to the simulation space. The planet is outside of the linear path to the target, but its gravity is strong enough to bend the asteroid's path and accelerate its speed. In order to complete this level the student must position the spring away from the planet and allow the asteroid to curve into the target. In level 3 , students are tasked with launching the asteroid so 
that it will hit a target located directly behind a midsized planet. This task can only be accomplished by using the gravitational properties of the planet to curve the asteroid around it. In level 4, learners are asked to "make the asteroid go around the planet twice." In this level a mid-sized planet is positioned 5-6 feet from the top of the spring. This final task builds on experiences and the observation of the asteroid's behavior of the previous levels. The asteroid's behavior in level 4 represents the natural creation of orbits and permits learners to observe how they are sustained through gravitational acceleration.

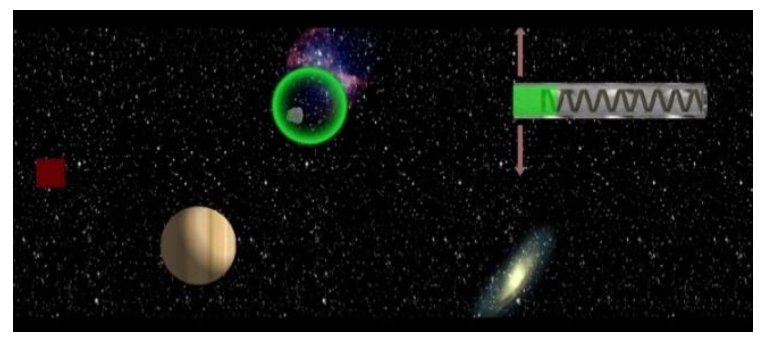

FIGURE 1. A screen shot of level 2 of MEteor.

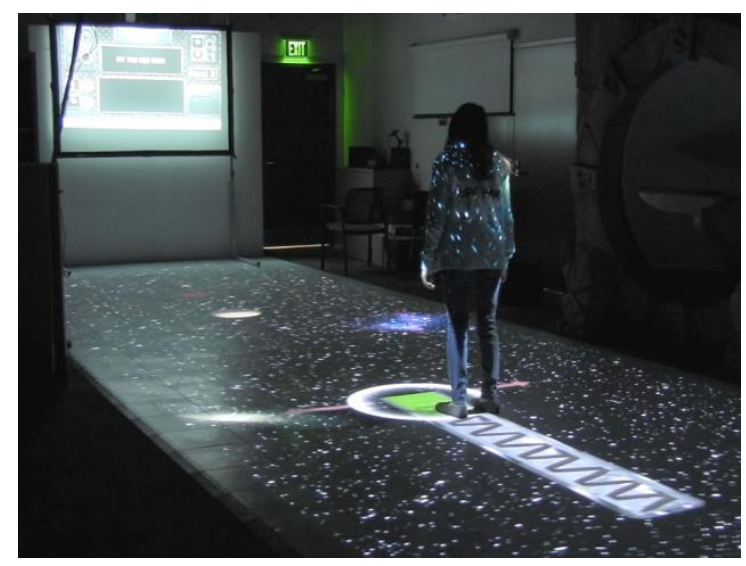

FIGURE 2. A participant in the immersive environment, adjusting the spring before launching the asteroid in level 3.

\section{RESULTS}

In order to examine the impact of the MEteor simulation and full-body interaction with physics concepts on student learning and engagement, we conducted a study in our lab where 133 students from 3 local middle schools used the simulation. Participants used the simulation in one of two modes: full-body mode where the participants used their bodies to predict and act out the trajectory of the asteroid, or desktop mode where participants used MEteor as a typical computer simulation and controlled the asteroid using a mouse. In this condition, the asteroid's trajectory had to be tracked with the mouse (otherwise the asteroid disappears). All procedures for both conditions were the same-the only difference was the degree to which participants engaged their bodies in using the simulation and enacting asteroid trajectories.

A great deal of data was collected about each participant's experience using the simulation-their movements, their learning, their reflections, etc. In this paper we focus on data collected pertaining to their attitudes, and their feelings of engagement and learning (see table 1). The first measure was an item we posed to participants as part of the post-questionnaire: they were asked simply to respond to the statement "I enjoyed using the simulation game" on a 6-point Likert Scale, with a 6 meaning that they strongly agree with the statement. Valid responses to this item were collected from 57 participants in the Desktop condition and 68 participants in the Whole-body condition. Participants in the whole-body condition responded significantly higher to this statement, $F(1,123)=4.14$, $p=.044$. Participants were also asked to respond to the statement "I felt the simulation game helped me to learn" on the same 6-point scale. Valid responses were obtained from 57 participants in the Desktop condition and 65 participants in the Whole-body condition. Participants in the Whole-body condition again responded significantly higher to this item, $F(1,120)=$ 7.94, $p=.006$.

Another type of measure used in this study to examine affective effects of the whole-body engagement was a set of 5 items about science attitudes that were administered both before and after using the MEteor simulation experience. Items were adapted from the Modified Attitudes Towards Science Inventory (ATSI) [13]. On a 6-point Likert scale participants were asked to respond to statements such as "I enjoy talking to other people about science" and "It is likely that science will be part of my job someday." The 5 items were similar but differed slightly from pre to post. Participants in both conditions received the same questions. Valid responses were obtained from 57 participants in the Desktop condition and 67 participants in the Wholebody condition. An average of the 5 pre-questionnaire items and an average of the 5 post-questionnaire items were taken for both conditions. A repeated measures ANOVA was used to compare the change in attitude from pre to post, and a marginally significant effect was found favoring the Whole-body condition, $F(1$, $122)=3.25, p=.074$. The strength of association between the Whole-body condition and attitude to science was found to be in the low to medium range $\left(\eta^{2}=.026\right)$. 
TABLE 1. Summary of Attitude and Engagement Measures

\begin{tabular}{lccccccc}
\hline & \multicolumn{2}{c}{$\begin{array}{c}\text { Desktop } \\
\text { Condition }\end{array}$} & \multicolumn{2}{c}{$\begin{array}{c}\text { Whole-Body } \\
\text { Condition }\end{array}$} & F & p & $\boldsymbol{\eta}^{2}$ \\
\hline & $\mathbf{M}$ & SD & M & SD & & & \\
\hline $\begin{array}{l}\text { Enjoyed } \\
\begin{array}{l}\text { Using } \\
\text { Simulation }\end{array}\end{array}$ & 4.72 & 1.13 & 5.13 & 1.13 & 4.14 & .044 & .033 \\
$\begin{array}{l}\text { Learned } \\
\text { From } \\
\text { Simulation }\end{array}$ & 4.30 & 1.09 & 4.86 & 1.12 & 7.94 & .006 & .062 \\
\hline $\begin{array}{l}\text { Pre- } \\
\begin{array}{l}\text { Science } \\
\text { Attitudes }\end{array}\end{array}$ & 4.62 & .57 & 4.45 & .80 & & & \\
\hline $\begin{array}{l}\text { Post } \\
\text { Science } \\
\text { Attitudes }\end{array}$ & 4.61 & .84 & 4.63 & .90 & & & \\
\hline
\end{tabular}

\section{CONCLUSION}

The results of this study indicate an affective advantage for physics educational environments that facilitate body involvement with conceptual development. The advantage specifically pertains to an environment that embeds learners within simulations of physical phenomena and prompts them to enact system functions, with representational supports that connect these enactments with formal knowledge in the domain. This kind of simulation experience seems to facilitate more positive attitudes and feelings of positive learning experiences compared to more traditional simulation interactions such as operating a desktop computer application. Further research on ways to utilize students' natural body-movements in physics education, as well as developing new measures on engagement and identity formation as it relates to science knowledge, is encouraged.

\section{ACKNOWLEDGMENTS}

Funding for the MEteor project was provided by the NSF (DRL1114621). Any opinions, findings, and conclusions or recommendations expressed in this material are those of the authors and do not necessarily reflect the views of the funding institutions.

\section{REFERENCES}

1. R. Lindgren and D. L. Schwartz, Int J Sci Ed, 31(3), pp. 419-438 (2009).

2. C. Dede, Educational Technology, 35, pp. 46-52 (1995).

3. S. de Freitas, and T. Neumann, Computers \& Education, 52(2), pp. 343-352 (2009).

4. C. Dede, M. Salzman, and R. Loftin, "The development of a virtual world for learning Newtonian mechanics", In Multimedia, hypermedia, and virtual reality, edited by $\mathrm{P}$. Brusilovsky, P. Kommers and N. Strutz, (Springer Verlag, Berlin, 1996), pp. 87-106.
5. W. K. Adams, S. Reid, R. LeMaster, S. B. McKagan, K. K. Perkins, M. Dubson, and C. E. Wieman, Journal of Interactive Learning Research 19, pg. 397ff. (2008).

6. D. Bodemer, R. Ploetzner, I. Feuerlein, and H. Spada, Learning and Instruction, 14, pg. 325ff. (2004).

7. R. W. Picard, S. Papert, W. Bender, B. Blumberg, C. Breazeal, D. Cavallo, T. Machover, M. Resnick, D. Roy, and C. Strohecker. BT Technology Journal, 22, pp. 253269 (2004).

8. C. E. Wieman, W. K. Adams, and K. K. Perkins, K. K., Science, 322(5902), pp. 682-683 (2008).

9. N. S. Podolefsky, K. K. Perkins, and W. K. Adams, Physics Education Research, 6 (2010).

10. S. Gallagher, How the body shapes the mind. (Oxford: Clarendon Press, 2005).

11. S. Goldin-Meadow, Child development perspectives $\mathbf{3}$, pp. 106-111 (2009).

12. A. M., Glenberg, T. Gutierrez, J.R. Levin, S. Japuntich, and M. P. Kaschak. Journal of Educational Psychology, 96, pp. 424-436 (2004).

13. M. H., Weinburgh, and D. Steele. Journal of Women and Minorities in Science and Engineering, 6, (2000). 